\title{
Accuracy of routine biomarkers and blood leucocytes count to assist diagnosis of COVID-19- associated pneumonia in adult patients visiting the emergency department
}

Cécile Maincent

Princess Grace hospital center

Frédéric Berthier

Centre Hospitalier Princesse Grace

Ryan Lukas Farhad

Centre Hospitalier Princesse Grace

Cristel Fissore-Magdelein

Centre Hospitalier Princesse Grace

Claire Claire Dittlot

Centre Hospitalier Princesse Grace

Nathalie Beau

Centre Hospitalier Princesse Grace

Jérémy Lépine

Centre Hospitalier Princesse Grace

Marjorie Lorillou

Centre Hospitalier Princesse Grace

Matthieu Dietz

Centre Hospitalier Princesse Grace

Mathieu Liberatore

Centre Hospitalier Princesse Grace

Atul Pathak

Centre Hospitalier Princesse Grace

Marc Marc Faraggi

Centre Hospitalier Princesse Grace

Sylvie Chaillou-Orpitz

Centre Hospitalier Princesse Grace

Olivia Keita-Perse

Centre Hospitalier Princesse Grace

Gilles Chironi

Centre Hospitalier Princesse Grace 


\section{Christophe Perrin}

Centre Hospitalier Princesse Grace

Yann-Erick Claessens ( $\nabla$ ye.claessens@gmail.com )

Centre Hospitalier Princesse Grace

\section{Original research}

Keywords: COVID, pneumonia, diagnosis, leucocytes count, basophilic count, eosinophilic count, fibrinogen, routine analysis, emergency medicine

Posted Date: June 16th, 2020

DOI: https://doi.org/10.21203/rs.3.rs-34817/v1

License: (c) (i) This work is licensed under a Creative Commons Attribution 4.0 International License.

Read Full License 


\section{Abstract}

Background To investigate whether routine biomarkers and blood leucocytes count could assist diagnosis of COVID-19-associated pneumonia in adult patients visiting the emergency department (ED).

Methods This monocentre retrospective study enrolled 254 patients with nasopharyngeal RT-PCR for SARS-COV-2, routine biomarkers (D-dimers, fibrinogen, C-reactive protein, procalcitonin, NTpro-BNP, cTnThs) and blood cell counts. Sensitivity and specificity were evaluated. An adjudication committee classified diagnostic probability as certain, probable, unlikely, and excluded, based on all available data, then distributed in 2 categories: high (certain and probable) and low probability (unlikely and excluded).

Results Between 25 th of February and 15 th of April, 2020, 254 of 388 patients could be analyzed. The adjudication committee classified 46 patients as definite, 18 as probable, 64 as unlikely, and 126 as excluded, corresponding to 64 high and 190 low probability. High and low probability patients differed for fibrinogen $(P<0.0005)$ and white blood cell counts, notably leucocytes $(P=0.0015)$, neutrophilic $(P=0.0036)$, lymphocytes $(P=0.0057)$, eosinophilic $(P=0.027)$, and basophilic $(P<0.001)$ counts. In a multivariate analysis, basophilic count $<25 / \mu \mathrm{L}$ (OR 3.048 [95\% Cl; 1.34-6.919]), neutrophilic count $<4000$ $/ \mu \mathrm{L}$ (OR 5.525 [95\%Cl; 2.20-13.855], and fibrinogen > 3g/L (OR 6355 [95\%Cl; 2.01-20.079] were independently associated with the diagnosis. Negative predictive values were 0.98 and 0.93 combining fibrinogen $(<3 \mathrm{~g} / \mathrm{L})$ and eosinophilic count $(<80 / \mu \mathrm{L})$, and fibrinogen and basophilic count $(<25 / \mu \mathrm{L})$, respectively.

Conclusion Changes in fibrinogen and white blood cells, notably basophilic count, showed interesting performance for the diagnosis COVID-19 associated pneumonia. Combining fibrinogen with either eosinophilic or basophilic count was helpful to exclude the diagnosis.

\section{Introduction}

In December 2019, the onset of an outbreak related to SARS-CoV-2 occurred, an unknown coronavirus detected in January 2020 [1,2] and responsible for a disorder termed COVID-19. Since then, COVID-19 has spread worldwide and is responsible for an unprecedented pandemic with major threat on global health, and social and economic stability [3].

COVID-19 has a large spectrum of symptoms. Most patients seem to experience mild or moderate flu-like disorder with cough, fever, and shortness of breath [4]. More severe presentations may occur and some patients develop an acute pneumonia that can lead to an acute respiratory distress syndrome (ARDS) $[5,6]$. Clinical signs and symptoms are poorly specific, and an early diagnosis is crucial to isolate the patients and treat them in dedicated units. Positive diagnosis mostly relies on detection of the virus by RT-PCR in the upper respiratory tract $[7,8]$ and suggestive images on chest CT-scan [9]. However, RT-PCR may be falsely negative in the early phase and CT abnormalities might be equivocal or lack specificity. Moreover RT-PCR results and CT-scan may be delayed and/or unavailable. As shortage of resources may occur during such a healthcare crisis [10], special attention should be paid to usual laboratory analysis in 
the management of patients suspected of COVID-19 infection during the phase of uncertain diagnosis. Several changes in biomarkers have been reported in COVID-19 infection: changes in leucocytes counts, notably lymphocytic and eosinophilic counts, elevation of D-dimers and cardiac biomarkers (since coronavirus may have cardiac and endothelial tropism and induce thrombosis and cardiovascular abnormalities). Professional and scientific societies and healthcare organizations have endorsed the use of routine biomarkers and blood cell count to assist physicians at bedside [11-14]. Whereas numerous studies reported the prognostic value of such laboratory data, a limited number were dedicated to diagnosis.

Therefore, while facing the outbreak, evaluating the role of routine biomarkers and leucocytes to guide diagnosis toward COVID-19 or alternative diagnoses is mandatory to better select patients since the Emergency Departments (ED) and fix hospital organization [15].

\section{Methods}

We designed a single center, retrospective, observational study conducted from February $25^{\text {th }}$. 2020 to April $15^{\text {th }} 2020$ in the Emergency Department (ED) of Princess Grace Hospital, a general hospital in Monaco. The study was monitored by the research department of our Hospital. No funding was obtained for this study. The ethical board held for the study approved the protocol and waived the need of a written informed consent for inclusion. The protocol was registered in the clinicaltrial.gov website under the MONACOVID-Biomarkers acronym (NCT04401241). The National laws for Ethics did not require informed consent. The study complied with STARD recommendations [16].

\section{Objectives}

The primary objective was to assess sensitivity of routine biomarkers and blood cell count for diagnosis of COVID-19-associated pneumonia in low and high probability groups for COVID-19-associated pneumonia classified by an adjudication committee.

Secondary objectives were i) to compare values of routine biomarkers and blood cell count amongst the four different categories of level of certainty; ii) to assess performance of combined routine biomarkers and blood cell count for diagnosis of COVID-19-associated pneumonia; iii) to assess whether usual biomarkers and blood cell count were associated with diagnosis of COVID-19-associated pneumonia using sensitivity analyses in predefinite subgroups chosen a priori; 1) when comparing definite versus excluded patients; 2 ) when comparing high vs. low probability patients, excluding bacterial infection (respiratory and extra-respiratory) in the low probability COVID-19-associated pneumonia group; 3) when comparing definite versus excluded probability patients, excluding bacterial infections (respiratory and extra-respiratory) in excluded patients.

\section{Adjudication committee}


An adjudication committee consisting of two independent senior experts in infectious diseases and pneumology retrospectively assigned the probability of COVID-19-associated pneumonia diagnosis using the 4-level Likert scale, based on data collected from baseline on standardized case report forms, results of SARS-Cov-2 specific RT-PCR, of low dose chest CT-Scan, and full access to all available data including patients' discharge summary. To note, the adjudication committee was blinded for classification by an independent senior radiologist of low dose chest CT-scan. A Likert scale allowed distribution of patients in four categories: 1) absence of COVID-19-associated pneumonia referred as excluded; 2) unlikely COVID-19-associated pneumonia; 3) probable COVID-19-associated pneumonia; and 4) definite COVID19-associated pneumonia. After adjudication committee classification, patients were distributed in two groups: low probability of COVID-19-associated pneumonia (excluded and unlikely) and high probability of COVID-19-associated pneumonia (probable and definite).

For this study, the gold standard was the diagnosis assessed by the adjudication committee. Alternative diagnoses were established for low probability COVID-19-associated pneumonia and classified as i) nonCOVID viral respiratory tract infection; ii) non-COVID bacterial respiratory tract infection; iii) respiratory tract disorder at the exclusion of infectious diseases; iv) extra-pulmonary infectious diseases; and v) miscellaneous.

\section{Study population}

For the study purpose and to ensure quality of the final adjudication committee diagnosis, we selected consecutive adults (18 years of age and above) visiting the COVID-19 dedicated ED who presented with clinically suspected COVID-19-associated pneumonia and had SARS-Cov-2 RT-PCR. Clinically suspected COVID-19-associated pneumonia was based on physician's judgment and fulfilling the following criteria: new onset of symptoms concordant with viral infection (at least one of the following: sweat; chills; myalgia; temperature $\geq 38^{\circ} \mathrm{C}$ or $<36^{\circ} \mathrm{C}$ or perception of fever; loss of smell and/or taste; diarrhea) and symptoms of an acute lower respiratory tract disorder (at least one of the following: cough; sputum production; respiratory rate $\geq 20$ per minute; dyspnea; chest pain; altered breathing sounds at auscultation). We selected patients whose presentation required a blood sample for global and severity assessment.

\section{Patient management and usual biomarkers and blood cell count}

Patients' management in the COVID-19-dedicated ED was based on local protocoled practices based on a collegial multidisciplinary decision if they presented with suspected COVID-19-associated pneumonia. Recorded baseline data consisted of demographic data (age; gender), medical history of coexisting conditions; treatments; symptoms; clinical findings and predetermined laboratory tests including: SARSCov-2 specific RT-PCR obtained on nasopharyngeal swab; low-dose chest CT-scan; standard blood analysis (complete blood count; hemostasis; metabolic panel; creatinine; blood urea nitrogen; liver enzymes); D-dimers (Vidas. Biomérieux); Procalcitonin (PCT); C-reactive protein (CRP); high sensitive cardiac troponin T; NT-pro-brain natriuretic peptide (NT-proBNP, all on Cobas, Roche diagnostics). 


\section{Microbiological samples}

Nasopharyngeal swabs were collected at admission and placed in a Middle Virocult MWE (Sigma $\left.{ }^{\circledR}\right)$ transport medium. Samples were kept at room temperature and sent to the laboratory immediately after collection. For the presence of SARS-COV-2, swabs were sent to french referent centres for virological analysis (Nice, Marseille, Paris). Routine microbiological examinations were performed at the discretion of the emergency physicians and included: presence of influenza $A$ and $B$ viruses and respiratory syncytial virus (RSV) $A$ and $B$ on nasopharyngeal swabs; blood culture; urine antigens for Streptococcus pneumoniae and Legionella pneumophila type l; serodiagnosis of Mycoplasma pneumoniae. These results were available to the adjudication committee.

\section{Low dose chest CT-scan data and COVID-19-associated pneumonia diagnosis classification}

Multidetector low dose thoracic CT-scan was performed for each individual patient and interpretation was recorded using a standardized report form. The low dose chest CT-scans were independently reviewed by a senior radiologist, blinded from other data, and classified for probability of COVID-19-associated pneumonia as 1) excluded; 2) unlikely; 3) probable; and 4) definite.

\section{Statistical analysis}

Baseline and follow-up characteristics were described by means and standard deviations (SD) or by median and interquartile range (IQR) for continuous variables with normal or with skewed distribution, respectively, and by percentages for categorical variables. Chi-square or Fisher exact tests were performed when appropriate for qualitative variables. The Student or Mann-Whitney tests were used to compare baseline characteristics and study outcomes between study groups for continuous variables with skewed distributions.

The distribution of values for usual biomarkers and blood cell count were determined in the different populations of patients using boxplots. The performances of current laboratory data in predicting definite COVID-19-associated pneumonia were evaluated by sensitivity analysis (definite vs excluded COVID-19associated pneumonia). CRP was evaluated at several cut-off points of $20 \mathrm{mg} / \mathrm{L}, 50 \mathrm{mg} / \mathrm{L}$, and $100 \mathrm{mg} / \mathrm{L}$, values used in previous studies [17]. Several cut-off points for PCT were chosen at the level of $0.10 \mu \mathrm{g} / \mathrm{L}$ [17] and at the two levels for suspected bacterial infection $0.25 \mu \mathrm{g} / \mathrm{L}$ and $0.50 \mu \mathrm{g} / \mathrm{L}$. Cut-offs for CTnT-hs were $14 \mathrm{ng} / \mathrm{L}$ and $50 \mathrm{ng} / \mathrm{L}$, as stated by the manufacturer. Cut-offs for D-dimers test were 500 $\mu \mathrm{g} / \mathrm{ml}$ and age-adjusted threshold [18]. Sensitivity, specificity, positive predictive values (PPVs), negative predictive values (NPVs), and likelihood ratio were calculated. Receiver operating characteristic (ROC) curves were drawn, area under the curve AUC was computed and optimal cut-off was identified by the maximization of the Youden's index, comparing laboratory results values in patients with excluded COVID-19-associated pneumonia and definite COVID-19-associated pneumonia. From these optimal cutoffs for laboratory results, sensitivity analyses were performed combining cut-offs. 
A multivariate logistic regression model was built to identify factors associated with having high probability of COVID-19-associated pneumonia as compared to having an excluded COVID-19-associated pneumonia diagnosis. All variables with a p value of $<0.15$ in the bivariate analysis were entered into a multivariate logistic regression with a backward stepwise approach; the discrimination was evaluated by the $\mathrm{C}$-index and its $95 \%$ confidence interval $(95 \% \mathrm{Cl})$ and the calibration was evaluated by the Hosmer Lemeshow goodness-of-fit test.

All tests were two-sided, and p-values below 0.05 were considered to denote statistical significance. All statistical analyses were performed using SAS 9.1. (SAS Institute, Cary, NC, USA).

\section{Results}

\section{Characteristics of the population}

During the study period, 388 patients with suspected COVID-19-associated pneumonia and nasopharyngeal swab for SARS-Cov-2 RT-PCR visited the dedicated ED. One hundred and thirty four patients could not be included since routine biological results were missing for 128 and 6 were under 18 years of age (Figure 1). Two hundred and fifty four adults patients with available routine laboratory results were selected for analysis (Table 1); 102 patients (39.7\%) were 65 years of age or older. The number of patients suffering from significant underlying disorders was 103 (41.5\%), including 43 $(17.3 \%)$ with pulmonary disorders. Cough $(n=163,64.1 \%)$, dyspnea $(n=109,42.8 \%)$, and perception of fever $(n=103,40.9 \%)$ were the most frequent symptoms. Pulmonary auscultation detected unilateral or bilateral crackles in 65 (32.5\%), and 33 (13.3\%) patients had anosmia / ageusia. SARS-CoV-2 RT-PCR was positive in 42 (16.5\%). Blood cultures were positive in 8 patients: Escherichia coli in 3, Staphylococcus in 2 (S. capitis, $n=1 ;$ S. hominis, $n=1)$; Enterococcus faecalis $(\mathrm{n}=2)$; Streptococcus intermedius $(\mathrm{n}=1)$.

\section{Low dose chest CT scan results}

Pulmonary infiltrates were described in $123(62.8 \%)$ out of 196 patients with low dose chest CT-scan. Ground glass opacities were reported in 68 patients, peripheral distribution in 66, linear condensation in 48 , and crazy paving in 8 . Most patients with CT-scan (81.3\%) had an extent of parenchymal abnormalities below $25 \%$. After being reviewed by an independent senior radiologist, low dose chest CTscan was classified as definite in 40 (33.3\%) and excluded in 64 (53.3\%).

\section{Adjudication committee classification}

Classification by the adjudication committee for COVID-19 associated pneumonia was definite in 46 (17.4\%), probable in 18 (6.8\%), unlikely in 64 (25.2\%), and excluded in 126 (49.6\%). This corresponded to 64 high probability and 190 low probability COVID-19-associated pneumonia. Among alternative diagnoses for low probability patients included, we observed 36 noninfectious pulmonary disorders 
(including 3 pulmonary embolisms), 26 viral lower respiratory tract infections (LRTI), 9 bacterial LRTI, 26 extra-respiratory bacterial infections.

\section{Performance of routine biomarkers and blood leucocytes count for diagnosis of COVID-19-associated pneumonia}

Among patients with high probability for COVID-19 associated pneumonia, PCT concentration was low, eosinophilic and lymphocytic counts were below normal range and levels of fibrinogen, D-dimers and CRP were increased. Lymphopenia $(\leq 1000 / \mu \mathrm{L})$ was observed in $26.0 \%$, eosinopenia $(\leq 10 / \mu \mathrm{L})$ in $28.0 \%$, high fibrinogen concentrations $(>3.42 \mathrm{~g} / \mathrm{L}$ ) in $55.3 \%$. When comparing high and low probability patients, a significant decrease was observed in nearly each leucocytes neutrophilic, lymphocytic, basophilic and eosinophilic counts; fibrinogen measurement was significantly elevated in high probability patients (Table 2). Distribution of these 6 variables amongst the 4-level Likert scale categories are reported in Figure 2. Global performance of these parameters remained modest and none had an AUC above 0.80 . Other parameters did not differ between the high and low probability groups.

Amongst all parameters, a drop in basophilic count showed valuable characteristics to ascertain diagnosis (Table 3). Indeed, positive likelihood ratios were 6.94 and 5.96 at a cut-off of 0 and $10 / \mu \mathrm{L}$, respectively. Performance for positive diagnosis was lower with other leucocytes counts (Table 4). To rule out the diagnosis, high neutrophilic and lymphocytes counts were of interest. Negative likelihood ratio was 0.46 for both neutrophilic count above $7500 / \mu$ l and lymphocytes count above $2500 / \mu$ l. Results for other parameters are detailed in Supplementary data. When comparing patients with definite or excluded COVID-19 associated pneumonia, similar results were observed (Table 3). A multivariate analysis showed interesting individual characteristics of basophilic counts, neutrophilic counts and fibrinogen measurement at the Youden's index value to help positive diagnosis of COVID-19 associated pneumonia (Table 5).

\section{Performance of routine biomarkers and blood leucocytes count for diagnosis of COVID-19-associated pneumonia, excluding bacterial infection}

To better assess sensitivity, we compared patients with high and low probability when bacterial infections were removed from the study population (Table 3). Removing bacterial infection decreased the performance of total leucocytes count (AUC 0.687 [0.607-0.767] vs. 0.666 [0.583-0.749]) and neutrophilic count (AUC 0.651 [0.569-0.733] vs. 0.616 [0.531-0.701]). Conversely, removing bacterial infection did not alter characteristics of eosinophilic count (AUC 0.653 [0.571-0.735] vs. 0.683 [0.601-0.765]), basophilic count (AUC 0.714 [0.635-0.793] vs. 0.726 [0.647-0.805]), lymphocytes count (AUC 0.637 [0.554-0.720] vs. 0.669 [0.586-0.752]), and fibrinogen (AUC 0.671 [0.583-0.759] vs 0.71 [0.623-0.797]). Similar effects were observed when bacterial infection were removed from comparison of definite and excluded COVID-19 associated pneumonia (Table 3 ).

Performance of combined parameters for diagnosis of COVID-19-associated pneumonia, excluding bacterial infection 
We assessed the accuracy of combining fibrinogen and different leucocytes counts at the Youden's index value. We observed that fibrinogen combined with eosinophilic count had interesting characteristics to exclude diagnosis of COVID-19-associated pneumonia, with NPV 0.98 [95\% Cl, 0.868; 0.9994](Se 98\%, NPV 98\%, LR- 0.007), and outperformed combination of fibrinogen and basophilic count, whose NPV was 0.93 (Se 93\%, LR- 0.22). Combination was poorly specific for both fibrinogen and eosinophilic count (Sp $26 \%$, PPV 0.32, LR+ 1.33), and fibrinogen and basophilic count (Sp 33\%, PPV 0.33, LR+ 1.39).

\section{Discussion}

Here we report the accuracy of leucocytes counts and routine biomarkers to assist diagnosis of COVID-19 associated pneumonia in patients visiting the emergency department with pneumonia-like symptoms. The major strength of the present study is the control group to whom COVID-19 patients were compared. Our results highlighted the ability of basophilic count to exclude or confirm the diagnosis. We also observed that neutrophilic, lymphocytes and eosinophilic counts, and fibrinogen had interesting characteristics. Combining fibrinogen with either eosinophilic or basophilic count was helpful to exclude the diagnosis of COVID-19 associated pneumonia. Cardiac biomarkers and D-dimers test were of limited values at the emergency department.

Several scientific societies and healthcare organisms have supported the use of common biological results to manage COVID-19 patients $[8,11-14]$. The value of leucocytes counts to assist diagnosis of COVID-19 has been advocated since the beginning of the outbreak. Drop in lymphocytes and eosinophilic counts has been proposed to guide diagnosis process. Lymphopenia has been reported as the most frequent abnormality $[19,20]$, observed in up to $82 \%$. The decrease in eosinophilic count has also been underlined [21]. A study comparing patients with COVID-19 $(n=52)$ and LRTI $(n=53)$ reported lower eosinophils count in COVID-19 (0.02 / $\mu \mathrm{L}$ vs. $0.05 / \mu \mathrm{L}, \mathrm{P}$ value 0.004$)$, and frequent eosinopenia $(78.8 \%$ vs. $35.8 \%, P$ value $<0.001$ ) [22]. In this study, leukocyte counts had no diagnostic value. Combining eosinopenia to clinical signs improved sensitivity and specificity ( $78.8 \%$ and $64.2 \%$, respectively), as did lymphopenia (48.1\% and $52.8 \%$ ). While our results are in accordance with these results, we showed that leucocytes could also be of interest. We also reported that low basophilic count frequently occurred and had good diagnostic performance. This abnormality has not been reported so far. So far, we have been unable to provide specific explanation. We believe that a drop in basophilic count should be investigated in other series of viral infection, including COVID-19. Combining eosinophilic count $(\leq 80 / \mu \mathrm{l})$ and fibrinogen ( $\geq 3 \mathrm{~g} / \mathrm{L}$ ) could help excluding diagnosis of COVID-19 in patients with a flu-like pneumonia. Indeed, we reported the good predictive values of fibrinogen measurements. Fibrinogen is associated with worse prognosis of COVID patients, as described for D-dimers test [23]. Activation of coagulation and major risk of venous thromboembolism are described in COVID patients, in relation with the so-called cytokines storm [24]. Therefore, increase in coagulation markers is foreseen. Interestingly acute fibrinous and organizing pneumonia (AFOP)-like pneumonia are described in SARS-Cov-2 infected patients [25]. Therefore it cannot be excluded that D-dimers increase could partly be related to the presence of fibrinogen in the lung compartment. 
In COVID-19 patients, PCT is mostly below $0.25 \mu \mathrm{g} / \mathrm{L}[12,19]$. In case of a superinfection, levels or PCT are usually measured above $0.5 \mu \mathrm{g} / \mathrm{L}$ and significantly elevated as compared to patients with a pure COVID pneumonia (OR 4.76 [95\% Cl, 2.74-8.29])[26]. Although we reported no difference in PCT concentration between different levels of certainty, the low concentrations advocate for a potent use for stewardship. In our population, PCT measurements significantly differed between patients with a definite diagnosis of COVID-associated pneumonia and those with a bacterial infection (0.08 [0.05-0.12] vs. 0.17 [0.06-1.32], $P$ value 0.0222 , data not shown). To note, this did not apply to CRP (P value 0.62 , data not shown). Despite results from previous studies [27], we have been unable to detect any difference between groups for cardiac biomarkers [27].

We acknowledge that our results have limitations. For this study, we used retrospective data because of the urge of the sanitary situation and the relative resolution of the pandemic. This obviously leads to some bias. First, this method elicits missing data among laboratory measurements. Second, 128 adult patients analyzed for the presence of SARS-COV-2 using RT-PCR could not be included because no routine laboratory analysis was ordered. These patients significantly differ from the population analyzed in this study since none was admitted. Therefore we did not captured all the population with flu-like syndrome but focused on patients with potential pneumonia. This explains that blood analysis was not ordered for some patients. Finally, we analyzed data available for attending physicians that obviously used them at bedside. Additionally, the adjudication committee may have utilized these laboratory results to classify patients for level of certainty. We previously reported such a methodology to classify community-acquired pneumonia [28]. Indeed, it was asked to adjudication committees to comment their decision for classification. It appears that classification mostly relied on RT-PCR and CT-scan for positive diagnosis; the committees seldom quoted the use of routine biological parameters to assist their decision.

\section{Conclusion}

Guidelines have endorsed the use of routine laboratory analysis to help physicians making a diagnosis of COVID-associated pneumonia. Our results underscored the significance of blood cell counts analysis, the notable value of fibrinogen, and advocate for the use of combined eosinophilic or basophilic count and fibrinogen measurement to exclude diagnosis. COVID-19 may become endemic, senior UN health official Mike Ryan declared on Wednesday, $13^{\text {rd }}$ of May, 2020. This announcement strengthens the need for physicians to get reliable results for data available in daily practice, and underlines the scope of the present study.

\section{Declarations}

\section{Ethical Approval and Consent to participate}

The ethical board held for the study approved the protocol and waived the need of a written informed consent for inclusion. The National laws for Ethics did not require informed consent. 


\section{Consent for publication}

All authors have critically read and commented on draft versions of the report, and approved the final version.

\section{Availability of supporting data}

Extensive access to data is available on request.

\section{Competing interests}

The authors declare no competing interests.

\section{Funding}

Not applicable.

\section{Authors' contributions}

YEC and FB developed the study design. CFM was responsible for laboratory data collection. YEC and FB had full access to the data and take responsibility for the accuracy of the data analysis. FB and performed the statistical analysis. All authors assisted with data interpretation. YEC performed the literature search and wrote the first draft of the paper. All authors have critically read and commented on draft versions of the report, and approved the final version.

\section{Acknowledgments}

We thank all patients for participating in this study, and members of the MONACOVID Study Group. Department of Anaesthesiology and Intensive Care Medicine: M Bourregba; JP Guerin; G Rousseau; I Rouquette. Department of Biology: C Fissore-Magdelein; S Gabriel-Solean. Department of Biostatistics: F Berthier. Department of Cardiologie: G Chironi; V Dupasquier; A Pathak. Department of Clinical Research: C Dugourd; M Nicolai; N Rijo. Department of Emergency Medicine: N Beau; YE Claessens; X Magdelein. Department of Gastrotrenterology: F Olyve. Department of Infectious diseases: S Chaillou-Orpitz; RL Farhad; O Keita-Perse. Department of Nuclear Medicine. M Dietz; M Faraggi. Department of Pneumology: 
J Lépine; M Lorillou; C Maincent; C Perrin. Department of Radiology: S Bertrand; P Brunner; C Dittlot; F Fuerxer; M Liberatore.

\section{References}

1. Stop the Wuhan virus. Nature. 2020;577(7791):450.

2. Zhu N, Zhang D, Wang W, Li X, Yang B, Song J, et al. A Novel Coronavirus from Patients with Pneumonia in China, 2019. N Engl J Med. 2020;382(8):727-33.

3. Chen Z, Cao C, Yang G. Coordinated multi-sectoral efforts needed to address the COVID-19 pandemic: lessons from China and the United States. Glob Health Res Policy 2020;5:22.

4. Huang C, Wang Y, Li X, Ren L, Zhao J, Hu Y, et al. Clinical features of patients infected with 2019 novel coronavirus in Wuhan, China. Lancet 2020;395(10223):497-506.

5. Chen N, Zhou M, Dong X, Qu J, Gong F, Han Y, et al. Epidemiological and clinical characteristics of 99 cases of 2019 novel coronavirus pneumonia in Wuhan, China: a descriptive study. Lancet 2020;395(10223):507-13.

6. Wang D, Hu B, Hu C, Zhu F, Liu X, Zhang J, et al. Clinical Characteristics of 138 Hospitalized Patients With 2019 Novel Coronavirus-Infected Pneumonia in Wuhan, China. JAMA 2020;323(11):1061-9.

7. Zheng S, Fan J, Yu F, Feng B, Lou B, Zou Q, et al. Viral load dynamics and disease severity in patients infected with SARS-CoV-2 in Zhejiang province, China, January-March 2020. BMJ 2020;369:m1443.

8. Clinical management of severe acute respiratory infection when novel coronavirus ( $\mathrm{nCoV}$ ) infection is suspected: interim guidance, 25 January 2020. Published January 25, 2020. Accessed March 20, 2020. https://apps.who.int/iris/handle/10665/330854

9. Chung M, Bernheim A, Mei X, Zhang N, Huang M, Zeng X, et al. CT Imaging Features of 2019 Novel Coronavirus (2019-nCoV). Radiology 2020;295(1):202-7.

10. Rowan NJ, Laffey JG. Challenges and solutions for addressing critical shortage of supply chain for personal and protective equipment (PPE) arising from Coronavirus disease (COVID19) pandemic Case study from the Republic of Ireland. Sci Total Environ 2020;725:138532.

11. Handbook of COVID-19 Prevention and Treatment. Chinese guidelines, 18/03/2020. alnap.org/helplibrary/handbook-of-covid-19-prevention-and-treatment.

12. Guan WJ, Ni ZY, Hu Y, Liang WH, Ou CQ, He JX, et al. Clinical Characteristics of Coronavirus Disease 2019 in China. N Engl J Med 2020;382:1708-20.

13. Qu JM, Wang C, Cao B; Chinese Thoracic Society Chinese Association of Chest Physician. Guidance for the management of adult patients with coronavirus disease 2019. Chin Med J 2020 doi:

10.1097/CM9.0000000000000899.

14. Interim Clinical Guidance for Management of Patients, CDC guidelines, 30/03/2020. www.cdc.gov/coronavirus/2019-ncov/hcp/clinical-guidance-management-patients.html

15. Her M. Repurposing and reshaping of hospitals during the COVID-19 outbreak in South Korea. One Health 2020. doi: 10.1016/j.onehlt.2020.100137. 
16. Bossuyt PM, Reitsma JB, Bruns DE, Gatsonis CA, Glasziou PP, Irwig LM, Lijmer JG, Moher D, Rennie D, de Vet HC; Standards for Reporting of Diagnostic Accuracy. Towards complete and accurate reporting of studies of diagnostic accuracy: the STARD initiative. BMJ 2003;326(7379):41-4.

17. Le Bel J, Hausfater P, Chenevier-Gobeaux C, Blanc FX, Benjoar M, Ficko C, et al. Diagnostic accuracy of $\mathrm{C}$-reactive protein and procalcitonin in suspected community-acquired pneumonia adults visiting emergency department and having a systematic thoracic CT scan. Crit Care 2015;19:366.

18. Righini M, Van Es J, Den Exter PL, Roy PM, Verschuren F, Ghuysen A, et al. Age-adjusted D-dimer cutoff levels to rule out pulmonary embolism: the ADJUST-PE study. JAMA 2014;311(16):1117-24.

19. Zhou F, Yu T, Du R, Fan G, Liu Y, Liu Z, et al. Clinical course and risk factors for mortality of adult inpatients with COVID-19 in Wuhan, China: a retrospective cohort study. 2020.

DOl:https://doi.org/10.1016/S0140-6736(20)30566-3

20. Qin C, Zhou L, Hu Z, Zhang S, Yang S, Tao Y, et al. Dysregulation of Immune Response in Patients With Coronavirus 2019 (COVID-19) in Wuhan, China. Clin Infect Dis ciaa248 https://doi.org/10.1093/cid/ciaa248

21. Zhang JJ, Dong X, Cao YY, Yuan YD, Yang YB, Yan YQ, et al. Clinical characteristics of 140 patients infected with SARS-CoV-2 in Wuhan, China. Allergy. 2020. doi: 10.1111/all.14238.

22. Lippi G, Plebani M. Laboratory abnormalities in patients with COVID 2019 infection. Clin Chem Lab Med 2020. pii: /j/cclm.ahead-of-print/cclm-2020-0198/cclm-2020-0198.xml. doi: 10.1515/cclm2020-0198.

23. Li Q, Ding X, Xia G, Geng Z, Chen F, Wang L, Wang Z. A simple laboratory parameter facilitates early identification of COVID-19 patients. doi: https://doi.org/10.1101/2020.02.13.20022830.

24. Vaninov N. In the eye of the COVID-19 cytokine storm. Nat Rev Immunol. 2020;20(5):277.

25. Copin M, Parmentier E, Duburcq T, Poissy J, Mathieu D, Lille COVID-19 ICU and Anatomopathology Group. Time to consider histologic pattern of lung injury to treat critically ill patients with COVID-19 infection. Intensive Care Med. 2020. doi:10.1007/s00134-020-06057-8

26. Lippi G. Procalcitonin in patients with severe coronavirus disease 2019 (COVID-19): A meta-analysis. Clin Chim Acta 2020;505:190-1.

27. Guo T, Fan Y, Chen M, Wu X, Zhang L, He T, et al. Cardiovascular Implications of Fatal Outcomes of Patients With Coronavirus Disease 2019 (COVID-19). JAMA Cardiol. 2020. doi: 10.1001/jamacardio.2020.1017.

28. Claessens YE, Debray MP, Tubach F, Brun AL, Rammaert B, Hausfater P, et al. Early chest CT-scan to assist diagnosis and guide treatment decision for suspected community-acquired pneumonia. Am J Respir Crit Care Med 2015;192(8):974-82.

\section{Table Legends}

Table 1. Characteristics of the study population. 
Table 2. Comparison of leucocytes counts, C-reactive protein, procalcitonin, fibrinogen, D-dimers, Nterminal pro-brain natriuretic peptide, and high sensitive cardiac troponin $\mathrm{T}$ in patients with high or low probability for COVID-19 associated pneumonia.

Table 3. Comparison of leucocytes counts, C-reactive protein, procalcitonin, fibrinogen, D-dimers, Nterminal pro-brain natriuretic peptide, and high sensitive cardiac troponin $\mathrm{T}$ in patients with high or low probability for COVID-19 associated pneumonia and excluded bacterial infections, and in patients with definite or excluded COVID-19 associated pneumonia, with or without bacterial infections.

Table 4. Performance of fibrinogen, lymphocytes, neutrophil, eosinophil, and basophil polymorphonuclear leucocytes, according to different cut-offs in the patients with high or low probability for COVID-19 associated pneumonia.

Table 5. Multivariate analysis of the characteristics of high and low probability COVID-19 associated pneumonia.

Supplementary data. Performance of CRP, PCT, D-dimers and cTnT-hs, according to different cut-offs in the patients with high or low probability for COVID-19 associated pneumonia.

\section{Tables}

Table 1. 
General characteristics

Age

Mean age (years)

$57.8 \pm 21.0$

$\geq 65$ years

$102(39.7)$

Sex

Female

$126(49.0)$

Male

$131(51.0)$

Nursing home resident

$8(4.0)$

Comorbidities

At least 1 comorbidity

$103(41.5)$

Chronic respiratory disease

43 (17.3)

Congestive heart failure

33 (13.3)

Kidney disease

$13(5.3)$

Neoplasia

$6(2.4)$

Liver disease

4 (1.6)

History of stroke

$10(4.0)$

Weight

Community-acquired pneumonia characteristics at inclusion

Antibiotics before ED visit

$44(17.2)$

Antiviral therapy before ED visit

$6(2.3)$

Symptoms duration before visiting ED (days)

$5.9 \pm 6.6$

Signs and symptoms in the ED

Cough

$163(64.1)$

Chest pain

$48(19.0)$

Expectoration

17 (6.7)

Dyspnea

$109(42.8)$

Chills

89 (35.6)

Headaches

60 (23.9)

Myalgia

$56(22.4)$

Crackles

53 (20.8)

Perception of fever

103 (40.9)

Anosmia / ageusia

33 (13.3)

Diarrhea

$61(24.4)$

Temperature

$37.4(0.9)$

Respiratory rate

$19.1(4.8)$

$\mathrm{SatO}_{2}$

$96.6(2.6)$

Heart rate

$88.2(17.1)$

Confusion

9 (3.5)

Pleural effusion

32 (14.8)

Microbiological data

Positive PCR SARS-Cov-2

42 (16.5)

Positive PCR Influenza A

$4(2.3)$

Positive PCR Influenza B

$6(3.4)$ 
Positive pneumococcal antigenuria

General laboratory data

Glycaemia (mmol/L)

$6.4 \pm 1.7$

Urea $(\mathrm{mmol} / \mathrm{L})$

$6.1 \pm 3.9$

$\mathrm{pH}$

$7.44 \pm 0.07$

$\mathrm{PaO}_{2}(\mathrm{mmHg})$

$74.2 \pm 23.3$

Haematocrit

$0.39 \pm 0.05$

Outcome

Discharge

Admission General ward

$126(49.6)$

Admission ICU

$119(46.9)$

28-day mortality

$8(3.2)$

Low dose CT-scan probability for COVID-19 associated pneumonia $(\mathrm{n}=193)$

Definite

$40(33.3)$

Probable

$5(4.2)$

Unlikely

$11(9.2)$

Excluded

$64(53.3)$

Table 2. 
White blood cell

counts

Leucocytes $\left(10^{3} / \mathrm{mm}^{3}\right)$

Neutrophils $\left(10^{3} / \mathrm{mm}^{3}\right)$

Eosinophils $\left(10^{3} / \mathrm{mm}^{3}\right)$

Basophils $\left(10^{3} / \mathrm{mm}^{3}\right)$

Monocytes $\left(10^{3} / \mathrm{mm}^{3}\right)$

Lymphocytes $2541470[998-\quad 1057[792-$ $\left(10^{3} / \mathrm{mm}^{3}\right)$

Biomarkers

C-reactive protein 2536.9 [1.4-41.8] 17.6 [4.1$(\mathrm{mg} / \mathrm{L})$

$51.4]$
$2557800[5950-6455[4440-8200[6760-0.687$ [0.607- 0.0015 10210] 8170] 10775]
$0.767]$ 2545349.5 [3770- $4116[3240-5538.5$ [40738447]

$31[8-72]$
$78.5[22-174.5]$

\begin{tabular}{|c|c|c|c|}
\hline $\begin{array}{l}\text { Procalcitonin } \\
(\mu \mathrm{g} / \mathrm{L})\end{array}$ & 198 & $\begin{array}{c}0.06[0.04 \\
0.12]\end{array}$ & $\begin{array}{c}0.07[0.05- \\
0.12]\end{array}$ \\
\hline
\end{tabular}

D-dimers $(\mu \mathrm{g} / \mathrm{L}) \quad 171 \quad 636$ [283- $\quad 886$ [439- 518 [251-1333] 0.613 [0.515- 0.4468 1333] 1475] 0.711]

Fibrinogen (g/L) $208 \quad 3.6[2.83-\quad 4.04[3.3-\quad 3.42[2.65-\quad 0.671[0.583-0.0005$ $\begin{array}{llll}4.36] & 4,75] & 4.19] & 0.759]\end{array}$

NTproBNP $20983.28[24.79-72.1[26.34-93.45[24.17-0.573$ [0.480- 0.3052 $(\mathrm{pg} / \mathrm{mL})$ 491] 210.75] 581.3] $0.666]$

cTroponin T-hs 2130.007 [0.003- 0.007 [0.005- 0.006 [0.003- 0.515 [0.427- 0.1745 (ng/L)
$0.015]$
$0.013]$

$0.016]$

0.603 ]

Table 3. 
High vs. Low probability. Definite vs. Excluded

excluded bacterial infections
Definite vs. Excluded. excluded bacterial infections

AUC $\quad P$ value

AUC $\mathrm{P}$

$\mathrm{N}$

value

$\begin{array}{lllllll}\text { Leucocytes } & 219 & 0.666[0.583- & 0.0143 & 170 & 0.735[0.644- & 0.0004\end{array}$

$0.749]$

$0.826]$

137

0.706

0.0057

$[0.609-$
0.803]

Neutrophils

$$
2180.616[0.531
$$$$
0.043
$$

169

0.701]

$1690.695[0.599-0.0012$

$0.791]$

136

0.646

0.0249

[0.544-

$0.748]$

\begin{tabular}{|c|c|c|c|c|c|c|c|c|c|}
\hline Eosinophils & 218 & $\begin{array}{c}0.683[0.601- \\
0.765]\end{array}$ & 0.0085 & 169 & $\begin{array}{c}0.727[0.634- \\
0.820]\end{array}$ & 0.001 & 136 & $\begin{array}{c}0.775 \\
{[0.685-} \\
0.865]\end{array}$ & 0.0002 \\
\hline Basophils & 218 & $\begin{array}{c}0.726[0.647- \\
0.805]\end{array}$ & $<0.0001$ & 169 & $\begin{array}{c}0.800[0.716- \\
0.884]\end{array}$ & $\begin{array}{c}< \\
0.0001\end{array}$ & 136 & $\begin{array}{c}0.816 \\
{[0.733-} \\
0.899]\end{array}$ & $<0.0001$ \\
\hline Monocytes & 218 & $\begin{array}{c}0.579[0.493- \\
0.665]\end{array}$ & 0.3389 & 169 & $\begin{array}{c}0.603 \text { [0.503- } \\
0.703]\end{array}$ & 0.4171 & 136 & $\begin{array}{r}0.599 \\
{[0.495-} \\
0.703]\end{array}$ & 0.4302 \\
\hline Lymphocytes & 218 & $\begin{array}{c}0.669[0.586- \\
0.752]\end{array}$ & 0.001 & 169 & $\begin{array}{c}0.685 \text { [0.583- } \\
0.749]\end{array}$ & 0.001 & 136 & $\begin{array}{c}0.734 \\
{[0.639-} \\
0.829]\end{array}$ & 0.0001 \\
\hline
\end{tabular}

C-reactive

$2170.668[0.585$

0.1532

168

$0.654[0.556-$

0.49

0.752]

135

0.742

0.1992

protein

0.751]

[0.648-

$0.836]$

\begin{tabular}{|c|c|c|c|c|c|c|c|c|c|}
\hline Procalcitonin & 174 & $\begin{array}{c}0.626[0.532- \\
0.720]\end{array}$ & 0.6306 & 137 & $\begin{array}{c}0.563[0.454- \\
0.672]\end{array}$ & 0.2553 & 115 & $\begin{array}{c}0.635 \\
{[0.524-} \\
0.746]\end{array}$ & 0.6279 \\
\hline D-dimers & 150 & $\begin{array}{c}0.658[0.560- \\
0.756]\end{array}$ & 0.1458 & 125 & $\begin{array}{c}0.647[0.533- \\
0.761]\end{array}$ & 0.2659 & 105 & $\begin{array}{c}0.711 \\
{[0.599-} \\
0.823]\end{array}$ & 0.0649 \\
\hline Fibrinogen & 180 & $\begin{array}{c}0.710[0.623- \\
0.797]\end{array}$ & $<0.0001$ & 146 & $\begin{array}{c}0.716 \text { [0.616- } \\
0.816]\end{array}$ & 0.0008 & 120 & $\begin{array}{c}0.778 \\
{[0.683-} \\
0.873]\end{array}$ & 0.0002 \\
\hline NTproBNP & 183 & $\begin{array}{c}0.544[0.452- \\
0.636]\end{array}$ & 0.7039 & 142 & $\begin{array}{c}0.615 \text { [0.507- } \\
0.723]\end{array}$ & 0.2794 & 118 & $\begin{array}{c}0.568 \\
{[0.455-} \\
0.681]\end{array}$ & 0.5015 \\
\hline
\end{tabular}

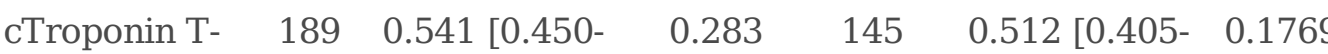

12

0.548

0.3195 
[0.437-

Table 4.

Page 19/24 
Parameters Cut-off Se Sp PPV NPV LR+ LR-

Neutrophils cut-off
\begin{tabular}{ll}
\hline $2500 / \mu \mathrm{L}$ & 17.4695 .2155 .0077 .493 .650 .87 \\
$\leq 4000 / \mu \mathrm{L}$ (Youden) 47.6276 .0640 .0081 .251 .990 .69 \\
$\leq 5000 / \mu \mathrm{L}$ & 60.3259 .0433 .0481 .621 .470 .67 \\
$\leq 7500 / \mu \mathrm{L}$ & 85.7130 .8529 .3586 .571 .240 .46 \\
$\leq 10000 / \mu \mathrm{L}$ & 93.6514 .8926 .9487 .501 .100 .43
\end{tabular}

\section{Lymphocytes cut-off}

$\leq 750 / \mu \mathrm{L} \quad 19.387 .7734 .2976 .391 .580 .92$

$\leq 1000 / \mu \mathrm{L}$ (Youden) 42.86 79.2640.91 80.542.07 0.72

$\leq 1500 / \mu \mathrm{L} \quad 68.2553 .1932 .8283 .331 .460 .60$

$\leq 2000 / \mu \mathrm{L} \quad 77.7831 .3827 .5380 .821 .130 .71$

$\leq 2500 / \mu \mathrm{L} \quad 93.6513 .8326 .7089 .671 .090 .46$

\section{Eosinophils cut-off}

0

22.2289 .3641 .1877 .422 .090 .87

$<15 / \mu \mathrm{L} \quad 42.8681 .9144 .2681 .052 .370 .70$

$<50 / \mu \mathrm{L} \quad 60.3261 .734 .5582 .271 .570 .64$

$<80 / \mu \mathrm{L}$ (Youden) $\quad 79.3748 .9434 .2587 .621 .550 .42$

$<120 / \mu \mathrm{L} \quad 82.5436 .1730 .2386 .081 .290 .48$

$\leq 250 / \mu \mathrm{L} \quad 92.0613 .326 .2483 .331 .060 .60$

\section{Basophils cut-off}

0

11.1198 .470 .0076 .766 .940 .90

$\leq 10 / \mu \mathrm{L} \quad 25.495 .7466 .6779 .305 .960 .78$

$\leq 25 / \mu \mathrm{L}$ (Youden) $\quad 61.9 \quad 75 \quad 45.3585 .452 .480 .51$

$\leq 50 / \mu \mathrm{L} \quad 84.1331 .9129 .2885 .711 .240 .50$

$\leq 75 / \mu \mathrm{L} \quad 95.249 .0425 .9785 .001 .050 .53$

$\leq 100 / \mu \mathrm{L} \quad 98.412 .6625 .3183 .331 .010 .60$

Fibrinogen cut-off

$>2.5 \mathrm{~g} / \mathrm{L}$

94.5519 .8730 .0690 .911 .180 .27 


\section{Parameters Cut-off Se Sp PPV NPV LR+ LR-}

\begin{tabular}{lc}
\hline$>3.0 \mathrm{~g} / \mathrm{L}$ (Youden) & 89.0939 .7435 .0090 .911 .480 .27 \\
\hline$>3.5 \mathrm{~g} / \mathrm{L}$ & 69.0953 .6435 .1982 .651 .490 .58 \\
$>4.0 \mathrm{~g} / \mathrm{L}$ & 52.7372 .1940 .8580 .741 .900 .65 \\
\hline$>5.0 \mathrm{~g} / \mathrm{L}$ & 2090.0742 .3175 .562 .010 .89
\end{tabular}

Youden corresponds to Youden's index, the optimized cut-off for sensitivity and specificity. Abbreviations. Se: sensitivity; Sp: specificity; PPV: positive predictive value; NPV: negative predictive value; LR+: positive likelihood ratio; LR-: negative likelihood ratio; Neutrophils: Neutrophil Polymorphonuclear Leucocytes; Eosinophils: Eosinophil Polymorphonuclear Leucocytes; Basophils: Basophil Polymorphonuclear Leucocytes.

Table 5.

\begin{tabular}{|c|c|}
\hline Parameters & OR $\quad[95 \% \mathrm{CI}]$ \\
\hline Basophils $<25 / \mu \mathrm{L}$ & 3.048 [1.34-6.919] \\
\hline Eosinophils $<80 / \mu \mathrm{L}$ & $2.16 \quad[0.85-5.43]$ \\
\hline Neutrophils $<4000 / \mu \mathrm{L}$ & $5.525[2.20-13.855]$ \\
\hline Fibrinogen $<3 \mathrm{~g} / \mathrm{L}$ & $6.355[2.01-20.079]$ \\
\hline Lymphocytes $<1500 / \mu$ & 0.84 [0.34-2.048] \\
\hline $\mathrm{CRP}<20 \mathrm{mg} / \mathrm{L}$ & $1.159[0.44-3.007]$ \\
\hline Gender & 1.12 [0.51-2.444] \\
\hline Age & $0.998[0.97-1.019]$ \\
\hline
\end{tabular}

Abbreviations. OR : Odds ratio; 95\% CI : 95\% confidence interval; Neutrophils: Neutrophil Polymorphonuclear Leucocytes; Eosinophils: Eosinophil Polymorphonuclear Leucocytes; Basophils: Basophil Polymorphonuclear Leucocytes; CRP : C-reactive protein. 
Supplementary data.

\section{Parameters' Cut-off Se Sp PPV NPV LR+ LR-}

\begin{tabular}{l}
\hline \multicolumn{2}{l}{ CRP cut-off } \\
\begin{tabular}{lr}
$>20 \mathrm{mg} / \mathrm{L}$ (Youden) $49,2166,8433,3379,621,480,76$ \\
$>50 \mathrm{mg} / \mathrm{L}$ & $26,9880,7532,0876,651,400,90$ \\
\hline$>100 \mathrm{mg} / \mathrm{L}$ & $11,1188,7725,0074,770,991,00$ \\
\hline PCT cut-off & \\
$>0.10 \mu \mathrm{g} / \mathrm{L}$ & 58.3330 .3923 .0867 .390 .841 .37 \\
$>0.25 \mu \mathrm{g} / \mathrm{L}$ & 94.4416 .8328 .8189 .471 .140 .33 \\
$>0.50 \mu \mathrm{g} / \mathrm{L}$ & 97.2216 .8329 .4194 .441 .170 .17
\end{tabular}
\end{tabular}

\section{D-dimers cut-off}

\begin{tabular}{ll}
\hline$>500 \mu \mathrm{g} / \mathrm{L}$ & 77.7248 .9433 .3386 .791 .520 .46 \\
\hline age-adjusted & 70.9753 .1933 .3384 .751 .520 .55
\end{tabular}

cTnT-hs cut-off

\begin{tabular}{lrr}
\hline $14 \mu \mathrm{g} / \mathrm{L}$ & 25 & 67.8920 .4573 .270 .781 .10 \\
\hline $50 \mu \mathrm{g} / \mathrm{L}$ & 2.78 & 91.7410 .0074 .070 .341 .06
\end{tabular}

Youden corresponds to the optimized cut-off for sensitivity and specificity. Abbreviations. Se: sensitivity; Sp: specificity; PPV: positive predictive value; NPV: negative predictive value; LR+: positive likelihood ratio; LR-: negative likelihood ration; CRP: C-reactive protein; PCT: procalcitonin; age-adjusted: age-adjusted cut-off over 50 years (age x10); cTnT-hs: high sensitive cardiac troponin T.

\section{Figures}




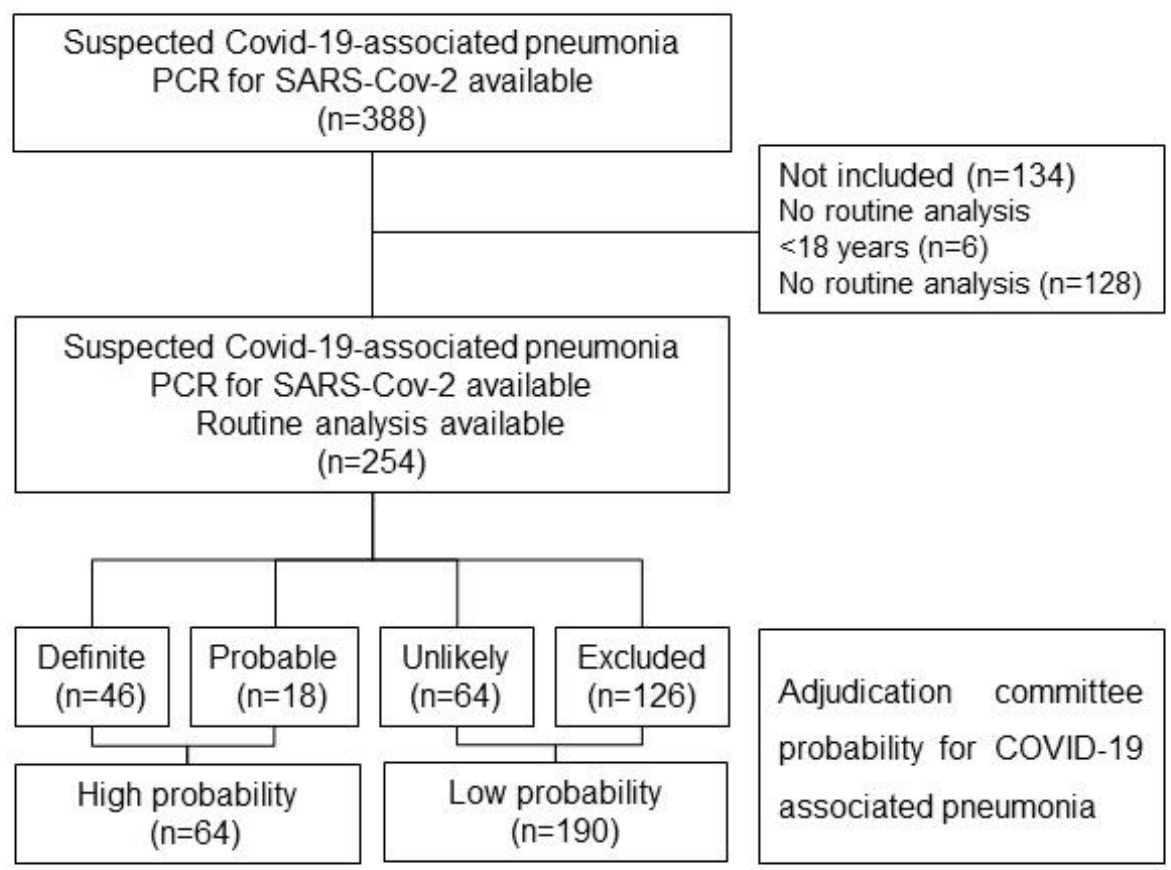

\section{Figure 1}

Chart flow. 

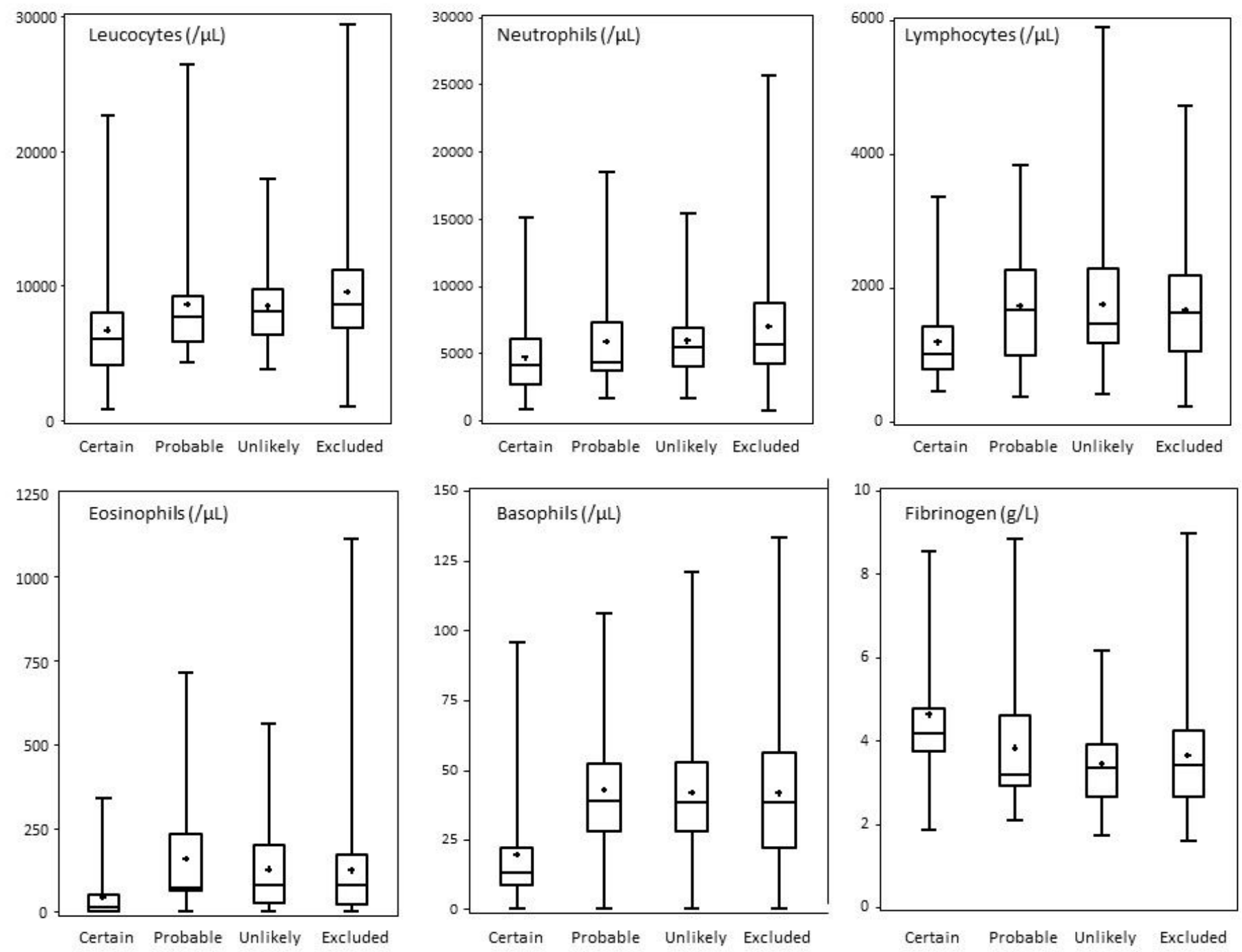

Figure 2

Distribution (boxplot) of leucocytes count, neutrophil count, eosinophil count, basophil count and fibrinogen measurement each level of diagnosis certainty of COVID-19-associated pneumonia according to diagnosis certainty classification (adjudication committee). 